\title{
Planejamento \& Gestão em Saúde: Situação Atual e Perspectivas para a Pesquisa, o Ensino e a Cooperação Técnica na Área
}

\author{
Carmem Fontes Teixeira ${ }^{1}$ \\ Marilene de Castilho Sáz
}

Resumo: Este artigo analisa a situação atual e as perspectivas da área de Planejamento e Gestão (P \& G) em Saúde no âmbito acadêmico, com o propósito de subsidiar o processo de rearticulação política e institucional dos núcleos de P \& G existentes nos Departamentos, Institutos e Escolas do campo da Saúde Coletiva. Tem seu ponto de partida na revisão dos movimentos antecedentes de articulação da área, retomando determinantes e resultados alcançados nas reuniōes realizadas durante os anos 80 e primeira metade dos anos 90 . Em seguida, expõe os resultados de um levantamento realizado junto a 40 núcleos de 26 instituiçôes acadêmicas, no segundo semestre de 1995, objetivando mapear a abrangência do P \& G em termos de áreas temáticas, sub-áreas e temas que vêm sendo trabalhados no âmbito da pesquisa, do ensino e da cooperação técnica interinstitucional. Apresenta uma classificaçào preliminar das áreas temáticas por ordem de importância, mensurada em termos da freqüência com que as palavras-chave a elas relacionadas sào mencionadas no levantamento realizado, e expõe uma caracterização inicial das atividades de pesquisa, ensino e cooperação técnica com os serviços no âmbito do $\mathrm{P} \& \mathrm{G}$. Finalmente, baseando-se nos relatórios dos encontros realizados, especialmente da Oficina de Trabalho para a rearticulação da área, ocorrida em outubro de 1995, discute as tendências observadas, à luz das questōes teórico-metodológicas e dos problemas e desafios formulados pelo processo de construçào do SUS.

Palavras-chave: Planejamento em Saúde; Gestào em Saúde; Saúde Coletiva; Pesquisa, Ensino \& Cooperaçào em Saúde Coletiva

Summary: This paper analyzes the current situation and the perspectives of the Health Planning and Management ( $P \& M$ ) area in the academic field in Brazil. Its main purpose is to support the establishment of political and institutional alliances among the existing Health $\mathrm{P} \& \mathrm{M}$ groups in the Brazilian Schools, Institutes and Departments of Public Health. It begins reviewing determinants and results of the efforts toward the development of solid connections between the institutions of the area in the 1980's and the early 1990's. Then, it shows the results of a survey conducted in $40 \mathrm{P} \& \mathrm{M}$ groups of 26 academic institutions in 1995 ,

1 Instituto de Saúde Coletiva, Universidade Federal da Bahia (UFBA), Salvador, Bahia.

2 Departamento de Administração e Planejamento em Saúde, Escola Nacional de Saúde Pública, Fundação Oswaldo Cruz, Rio de Janeiro. 
aimed at identifying the scope of $\mathrm{P} \& \mathrm{M}$ area in Brazil, taking into account the thematic areas and themes addressed by research projects, teaching activities and interinstitutional technical cooperation efforts. This paper also ranks the thematic areas based on the frequency in which their associated keywords are mentioned in the answers to the survey. A general overview of the research, teaching and technical cooperation activities in the Health Planning and Management area is given. Finally, the observed trends in the area are discussed, considering the theoretical and methodological problems and challenges incurred by the implementation process of the Brazilian Unified Health System (SUS).

Keywords: Health Planning; Health Management; Public Health; Research, Teaching and Technical Cooperation in Public Health

\section{1 - Introdução}

A constituição da Saúde Coletiva, enquanto campo de saber e práticas estreitamente vinculadas ao processo político de luta pela Reforma Sanitária Brasileira (Teixeira, 1988), tem como um dos seus eixos disciplinares a Administração e Planejamento em Saúde, área de produção e reprodução de conhecimentos e tecnologias no âmbito da organização social das práticas de saúde. Suas aplicações se dão, assim, em vários planos e níveis, descle o plano político mais geral da formulação de políticas setoriais e desenho do sistema de saúde até a singularidade das relações estabelecidas no processo de trabalho em saúde e em sua organização.

A abrangência e complexidade desta área tem se evidenciado pela incorporação de distintas abordagens teórico-metodológicas provenientes das ciências sociais, como a economia, as ciências políticas, a história, a sociologia e a antropologia, tendo como eixo comum a busca de compreensão, explicação e intervenção sobre os problemas e desafios postos pelas transformações na organização e gestão dos serviços e sistemas de saúde nas sociedades contemporâneas.

As temáticas abordadas incluem, assim, questões relacionadas ao estudo do papel do Estado na saúde; às políticas e à organi- zação institucional do setor saúde ou do sistema de saúde; às formas de financiamento e gestão dos serviços; à organização da prestação de serviços e aos modelos assistenciais; ao processo de trabalho/práticas profissionais em diversos níveis; à formação de pessoal; ao desenvolvimento científico e tecnológico, especialmente no que se refere às metodologias, técnicas e instrumentos de planejamento e gestão de sistemas e serviços; aos métodos e técnicas de avaliação e controle de eficiência, eficácia, efetividade e qualidade das ações, serviços, programas e sistemas de saúde etc.

A diversidade de temáticas e, principalmente, de abordagens teórico-metodológicas tem sido um dos desafios para a compreensão do próprio desenvolvimento científico e institucional da área, indicando que, neste processo, têm convergido distintas perspectivas, cujas origens e finalidades nem sempre permitiram uma articulação coerente $e$ orgânica.

A partir da criação da Associação Brasileira de Pós-Graduação em Saúde Coletiva ABRASCO, em 1979, e considerando a complexidade teórico-metodológica da área e a necessidade política de se aperfeiçoarem continuamente os saberes e as tecnologias visando a intervenção no sistema de saúde, num contexto de redemocratização do país, foram desencadeadas várias iniciativas com o obje- 
tivo de articular a área ${ }^{3}$. Buscava-se a criação de mecanismos de intercâmbio ou trabalho entre os diversos núcleos, que favorecessem tanto o desenvolvimento científico-técnico na área do Planejamento e Administração, quanto permitissem a definição coletiva de estratégias político-institucionais para o enfrentamento e superação dos problemas e obstáculos que se iam configurando no processo político setorial e na base organizacional e operativa do sistema de serviços de saúde.

Numa análise preliminar do desenvolvimento da área, pode-se dizer que esses movimentos obedeceram, de um modo geral, à evolução da conjuntura em saúde, reproduzindo os fluxos e refluxos do processo político setorial mais amplo. Assim, a partir do contexto político desfavorável ao SUS que marca o final dos anos 80 e início da década de 90 , observa-se, nos últimos anos, especialmente após o desencadeamento do processo de Municipalização das açôes e serviços de saúde, a retomada da preocupação com o fortalecimento dos processos e sistemas de planejamento setorial, e também com a rearticulação acadêmica cla área, em torno de questôes relacionadas à pesquisa, ao ensino e à cooperação técnica no processo de implementação do SUS. As várias reuniões promovidas pela ABRASCO, duas das quais em conjunto com o Ministério da Saúdé, são expressões da retomada dessa discussão. Além

3 Como principais destacam-se a I Reunião Nacional sobre Ensino e Pesquisa em Administraçào e Planejamento na Área da Saúde Coletiva, realizada en setembro de 1982, em Nova Friburgo/RJ; o Curso de Atualização para Docentes e Pesquisadores em Planejamento de Saúde, realizado em novembro de 1983, em Águas de Lindóia/ SP e, nesta mesma cidade, mas já em 1987, o Seminárió "A Epidemiologia e o Planejamento na Unificação do Sistema de Saúde no Brasil".

4 Seminário "O Processo de Planejamento na Construção do SUS", Brasília, maio de 1993 e Oficina de Trabalho "O Processo de Planejamento na Construção do SUS", Recife, outubro de 1993. disso, durante os Congressos de Saúde Coletiva e os Congressos de Epidemiologia realizados neste período, ocorreram algumas reuniões e oficinas de trabalho sobre temas específicos 5 .

A preocupação no sentido de rearticulação da área foi especialménte dominante no Congresso da ABRASCO em Recife, em 1994, quando espontaneamente foi realizada uma reunião entre pares, na qual surgiu a proposta de realização de uma Oficina de Trabalho com o objetivo de promover a rearticulação da área de Planejamento e Administração em Saúde. Para a organização desta Oficina, foí indicado um Grupo de Trabalho composto por representantes de diversos núcleos acadêmicos.

O ponto de partida para o trabalho deste grupo foi a identificação da questão central que vem motivando os núcleos interessados nesta rearticulação, qual seja, sua capacidade de resposta - em termos de produção de conhecimentos/tecnologias, formação de pessoal e cooperação técnica interinstitucional - às demandas/problemas atuais do sistema de saúde, antecipando-se, inclusive, aos problemas potenciais e estratégicos que podem ser vislumbrados nos cenários que hoje se clelineiam para a saúde no país. A resposta a essa questão exige, em primeiro lugar, um conhecimento da situação atual dos núcleos acadêmicos, ponto de partida para a formulação de propostas de articulação que possam vir a fomentar o desenvolvimento da pesquisa, do ensino e da cooperação técnica neste campo, tendo como propósitos o avanço téorico-metodológico da área e, particularmente, a contribuição crítica e criativa ao

\footnotetext{
5 Aqui cabe destacar, por sua abrangência temática e ênfase nas alternativas de gestào em saúde, a Oficina de Trabalho intitulada "Redefinição de Papéis, Reorganização Institucional e Planejamento no Sistema de Saúde: Novos desafios", realizada enquanto atividade de PréCongresso do IV Congresso Brasileiro de Saúde Coletiva, Recife, 1994
} 
processo de transição do sistema de saúde em direção ao SUS.

Sob essa perspectiva o Grupo de Trabalho decidiu realizar um levantamento da situação atual da pesquisa, ensino e cooperação técnica nos núcleos acadêmicos de Saúde Coletiva existentes no país. Os resultados deste levantamento ${ }^{6}$ foram o ponto de partida para o debate que se travou na Oficina de Trabalho para a rearticulação da área, realizada em outubro de 95, em São Paulo, ocasião em que foram discutidas questões relacionadas aos desafios e perspectivas teóricas e práticas, bem como se formularam propostas para o desenvolvimento das diversas linhas de trabalho nesta área.

O resultado desse trabalho constitui a "matéria-prima" a partir da qual foi elaborado o presente artigo. O item 2 traz uma descrição sumária da metodologia utilizada no levantamento da situação atual dos núcleos e os elementos de referência que foram incorporados na discussão dos resultados. O item 3 apresenta uma revisão do desenvolvimento histórico recente da área de Planejamento \& Gestão ( $P$ \& G) em Saúde, e um delineamento preliminar de sua abrangência atual, em termos de áreas temáticas, sub-áreas e temas de estudos, com base no levantamento realizado. $O$ item 4 traz uma caracterização das atividades de Pesquisa, Ensino e Cooperação Técnica realizadas atualmente pelos núcleos acadêmicos, e o item 5 contém a discussão das tendências identificadas, à luz dos desafios téorico-metodológicos e político-práticos no contexto atual de construção do SUS. Finalmente, o item 6 apresenta as principais propos-

\footnotetext{
- Com base na consolidaçào e análise das respostas ao questionário, foi produzido o documento "Situaçào Atual da Área de Planejamento e Administraçào em Saúde nas Instituições/Núcleos de Pós-Graduaçào em Saúde Coletiva do País", distribuído aos participantes da Oficina para a Rearticulação da Área de Planejamento e Administração em Saúde no País, USP, 26 e 27 de outubro de 1995.
}

tas da Comissão de P \& G, elaboradas a partir do debate desencadeado com a Oficina.

\section{2 - Metodologia}

A análise da situação atual e perspectivas do Planejamento e Gestão em Saúde no campo acadêmico teve como ponto de partida a identificação dos núcleos institucionais que trabalham atualmente com temáticas da área. Com base no Catálogo da ABRASCO, foi enviado, para cerca de 50 núcleos nas várias regiões e estados do país, um questionário aberto que solicitava a identificação das áreas temáticas trabalhadas em "Planejamento e Administração em Saúde" (denominação que constou do questionário) e das respectivas atividades de ensino, pesquisa e cooperação técnica desenvolvidas, além da relação dos pesquisadores/docentes que desenvolvem atividades na área.

As respostas ao questionário permitiram a identificação de 40 núcleos, distribuídos em 26 instituições (Anexos 1 e 2), a maioria das quais localizadas na regiào Sudeste, envolvendo um conjunto de 329 profissionais. A distribuição territorial e a composição dos núcleos é extremamente heterogênea, observando-se uma variação de 1 a 30 participantes por núcleo/instituição, com maior concentração de núcleos e pesquisadores na região Sudeste, seguida pelas regiões Nordeste e Sul. Chama a atenção a não inclusão da região Centro-Oeste, onde sabidamente existem núcleos com atividades em $\mathrm{P} \& \mathrm{G}$; não tendo havido, porém, respostas ao questionário.

Os 40 núcleos identificados estão localizados em 17 cidades. Nos estados das regiões Norte e Nordeste, localizam-se nas capitais, com exceção da Bahia onde, além de Salvador, foi identificado um núcleo em Ilhéus. Na região Sudeste o mesmo não acontece. No Rio de Janeiro, além dos núcleos localizados na capital, registrou-se um em Niterói. Em Minas Gerais, dois se situam em Belo Hori- 
zonte e outro em Viçosa. Em São Paulo, existem núcleos de $\mathrm{P} \& \mathrm{G}$ em Campinas, Ribeirão Preto, Botucatu, além da capital. Na região Sul, registraram-se dois núcleos no Paraná (Curitiba e Londrina) e quatro no Rio Grande do Sul, sendo um deles em Caxias do Sul e os demais em Porto Alegre.

As respostas ao questionário permitiram, em primeiro lugar, que se obtivesse um mapeamento da abrangência atual da área de $P \& G$, aliás um dos objetivos do levantamento, dada a hipótese preliminar de que está ocorrendo um alargamento do campo de investigação e práticas, a partir da inclusão de novas temáticas e da diversificação das temáticas mais "tradicionais" relacionadas ao Planejamento e à Administração em Saúde.

Com base na indicação das temáticas com que cada núcleo trabalha, foi estabelecida uma matriz de agregação a partir da identificação de "palavras-chave". Este primeiro agrupamento, que procurou manter a maior fidelidade possível à forma como os núcleos enunciaram suas áreas temáticas, resultou em 49 grupos temáticos, com diferentes graus de generalidade/especificidade. Posteriormente, estes grupos foram agregados em oito grandes "grupos temáticos", aos quais se denominou "áreas", por sua vez subdivididas em "sub-áreas" e "temas" (Anexo 3), de modo a se evitar que determinados temas "desaparecessem" quando da agrupação por área e sub-áreas. Os diferentes níveis de agregação não obedeceram a uma única lógica ou critério de recorte. Inicialmente, pensou-se em considerar como critério para abertura de sub-áreas os diversos enfoques teórico-metodológicos passíveis de adoção quando do tratamento temático. No entanto, pelas próprias limitações do instrumento de coleta utilizado, não foi possível identificar os enfoques empregados na maioria das citações. Deste modo, o que se usou foi uma lógica mista de abertura de áreas e sub-áreas, em que o número de citaçòes por palavras-chave constituiu também um critério importante.
As respostas ao questionário também permitiram a caracterização das linhas de pesquisa que vêm sendo desenvolvidas, das atividades de ensino de graduação e pós-graduação, em termos de disciplinas e cursos, e dos projetos e atividades de cooperação técnica interinstitucional, inclusive com a identificação das instituições envolvidas. A análise dessas atividades levou em conta sua distribuição pelas diversas áreas e sub-áreas temáticas. A apresentação desses resultados obedece a uma certa hierarquização das distintas áreas, determinada pela freqüência de citaçōes a elas referidas - o que indica a importância relativa de cada área enquanto concentradora das atuais práticas de docência, investigação e cooperação.

Finalmente, a discussão da situação observada levou em conta as questões que vêm sendo formuladas nas reuniões específicas da área de $P$ \& $G$ nos últimos anos, em dois planos: o desenvolvimento teórico-metodológico do P \& G em Saúde e os desafios político-institucionais derivados do processo de construção do SUS.

\section{3 - P \& G em Saúde: Desenvolvimento e Abrangência atual da Área}

\section{1 - Constituição e Desenvolvimento da Área de Administração e Planejamento em Saúde}

A utilização de noções, métodos e técnicas oriundos da Teoria Geral da Administração na organização dos serviços sanitários pode ser identificada já nos primórdios do movimento pela Saúde Pública, tendo se desenvolvido, no Brasil, ainda no ínicio do século, no período campanhista. No pós-guerra, introduziramse as concepções e técnicas da Administração Hospitalar, em função da crescente importância do hospital no conjunto da organização social dos serviços. 
No entanto, a emergência de uma reflexão teórico-metodológica mais sistemática sobre este conjunto de saberes e práticas, que levasse em conta a especificidade das questões de saúde, só veio a ocorrer, na América Latina e no Brasil, com o movimento pelo Planejamento em Saúde (Paim, 1983), a partir dos anos 60, tendo como marco o documento Programación de la Salud: Problemas Conceptuales y Metodológicos (OPS/OMS, 1965), amplamente conhecido como o Método CENDES-OPAS. É também nos anos 60 que se dá a incorporação da Administração Sanitária ao ensino médico, quando, sob a influência dos movimentos preventivista e de medicina comunitária, a reforma universitária torna obrigatória a criação dos Departamentos de Medicina Preventiva e Social.

Os desdobramentos teórico-metodológi$\cos$ derivados da crise da planificação, no contexto da crise do Estado e do modelo desenvolvimentista, resultaram na ampliação e diversificação da reflexão crítica neste campo. Observa-se, assim, a transição da micro-economia para o enfoque sistêmico, oriundo das teorias da organização e, posteriormente, a incorporação das ciências políticas ao entendimento das questões de saúde, particularmente ao instrumental metodológico do planejamento e administração. Discutindo especificamente a evolução no plano epistemológico do planejamento em saúde, Rivera (1989) chama a atenção para o caráter dialético desse processo, onde a evolução de uma visão normativa e de nível micro para uma visão macro e de natureza estratégica se dá através da superação dos elementos anteriores pelos novos elementos incorporados.

Durante os anos 70, especialmente a partir da segunda metade da década, a reflexão crítica na área encontra-se crescentemente vinculada ao desenvolvimento do chamado "movimento sanitário" no país, de certo modo refletindo e ao mesmo tempo alimentando não necessariamente de modo simultâneo os rumos do projeto reformador em saúde.
Neste processo, como aponta Teixeira,

"à medida que o projeto sanitário se aproximou da prática de planejamento e organização dos serviços, defrontou-se com novos atores em um cenário mais amplo: por um lado, os agentes de saúde trabalhando na base dos projetos de extensão de cobertura e os políticos interagindo no âmbito dos sistemas locais e estaduais de saúde; por outro, os produtores privados, que até aquele momento mantinham-se afastados do debate (...)" (Teixeira, 1988, p. 200).

É assim que, nos anos 80, principalmente a partir de 1985, assiste-se, paralelamente ao esforço de ampliação das bases de sustentação política do movimento sanitário - através da articulação de atores diversos em torno das mudanças propostas no arcabouço jurídico-político do sistema - e à ocupação dos cargos de direção das principais instituições do setor por profissionais ligados ao projeto de Reforma Sanitária, a crescente difusão do enfoque estratégico como orientador das práticas de planejamento e gestão setoriais. O conflito, o poder, a pluralidade e a incerteza passam, assim, à condição de categorias centrais no desenvolvimento teórico-metodológico da área.

Do ponto de vista da organização acadêmica e institucional da área, os anos 80 marcam o início do processo, tendo sido realizadas, como já apontado, algumas reuniōes específicas. A primeira delas ocorreu em 1982, em Nova Friburgo (ABRASCO, 1983), e tratava especificamente de promover uma primeira avaliação da situação existente quanto ao ensino e pesquisa na área, bem como discutir o perfil de seus docentes e pesquisadores. Outro momento importante de discussão teórico-metodológica e intercâmbio de experiências na área se deu no ano seguinte, em um curso, promovido pela ABRASCO, de atualização para docentes e pesquisadores em planejamento de saúde, atendendo a uma reco- 
mendação emanada da reunião de 82 (ABRASCO, 1984). Destaca-se ainda, em 1987, e no contexto da "politização" em torno do movimento pela Reforma Sanitária, a realização de um seminário cujo tema específico foi a articulação entre a Epidemiologia e o Planejamento de Saúde no processo de construção do novo sistema de saúde (ABRASCO, 1987).

A análise dos documentos relativos a esses eventos indica o quanto o desenvolvimento acadêmico da área se mostra intrinsecamente relacionado à evolução da conjuntura setorial, com reflexos não apenas nas temáticas e problemas prioritários - o que é esperado - como também nas possibilidades de desenvolvimento e pesos diferenciados que iam apresentando, nos diferentes momentos, as atividades de ensino, pesquisa e cooperação.

Assim, o início da década de 80 ainda caracteriza um período de implantação e fortalecimento dos núcleos de Saúde Coletiva, particularmente dos grupos acadêmicos ligados à área de Administração e Planejamento. Neste sentido, os esforços voltavam-se para a formação de quadros e difusão de informações e conhecimentos nesta área. A atividade de ensino era predominante. Reveladores dessa preocupação dominante com a formação de quadros acadêmicos são, por exemplo, a identificação, como principal dificuldade para o desenvolvimento da área, da falta de suporte bibliográfico adequado (Temporão \& Rivera, 1983), assim como as três recomendações feitas à ABRASCO, emanadas da primeira reunião da área: elaboração de um livro-texto sobre Administração e Planejamento em Saúde; criação de uma "Comissão Editorial em Administração e Planejamento de Saúde" (esse foi o caráter, na verdade, da primeira Comissão de Administração e Planejamento da ABRASCO), encarregada de coordenar a produção e divulgação de material bibliográfico (textos técnico-científicos e documentação política de maior peso produzida no se- tor); além da realização do curso, já mencionado, de aperfeiçoamento na área para docentes e pesquisadores.

Naquele contexto de insuficiência (qualitativa e quantitativa) de quadros acadêmicos em Administração e Planejamento em Saúde, não é de surpreender que a atividade de pesquisa fosse tão incipiente, como revelam o levantamento e a reunião realizados em 82 . Além disso, é interessante observar que as sugestōes quanto a linhas/temáticas de investigação a serem desenvolvidas eram formuladas exclusivamente enquanto atividades a serem implementadas a partir (ou no interior) dos cursos (Especialização em Saúde Pública, Residência, Mestrado e Doutorado).

Do mesmo modo, e embora constituísse já objeto de preocupação, a atividade acadêmica de cooperaçào técnica, naquele momento, era praticamente inexistente. Se, aparentemente, a conjuntura recente de redemocratização da sociedade colocava, por um lado, em pauta a necessidade de aproximação com os serviços, por outro, era ainda muito embrionária no sentido de permitir uma maior permeabilidade destes à academia e eliminar as desconfianças desta com relaçào àqueles. Assim, é interessante observar nos documentos do início da década de 80 a ênfase na necessidade de intervir nos serviços, de uma maior aproximação dos cursos com relação aos mesmos, de desenvolvimento de pesquisas operacionais (ou aplicadas aos serviços) - "Como ocupar tecnicamente os espaços que estão surgindo no seio da sociedade, dados pelo avanço do processo político de democratização?" (ABRASCO, 1983, p. 167) —, ao lado de observaçōes como: "Isto requer uma análise bem cuidadosa" (ABRASCO, 1983, p. 168), a respeito da tendência de crescimento da intervenção técnica em órgãos governamentais e assessoria a grupos politicamente organizados. De todo modo, o relatório final da I Reunião da área não deixa de recomendar a inserção de docentes e instituições formadoras na estrutura de órgãos prestadores 
de serviços, chegando inclusive a listar os principais órgãos onde poderiam ser clesenvolvidas atividades de consultoria, assessoria e participação em comissões, treinamentos etc.

Do ponto de vista da abrangência temática da área, as análises feitas na época sobre os conteúdos dos cursos, bem como as sugestões de temas para o ensino e a investigaçào, revelam a preocupaçào em responder a uma conjuntura de democratização, integrando a participação popular nos processos de planejamento e democratização da gestão dos serviços. Assim, critica-se, por exemplo, a predominância, nos cursos de Especialização em Saúde Pública e Residência em Medicina Preventiva e Social, de conteúdos da área de Administração Geral, em detrimento daqueles relativos ao processo decisório e ao desenvolvimento do Planejamento Econômico e Social no país, e àqueles relativos aos métodos e técnicas de planejamento. Sugere-se ainda a inclusào de conteúdos que permitam a discussão das políticas em nível local, assim como das principais questòes conjunturais. Com relaçào às sugestòes de temáticas para a investigação, destacam-se as preocupações com a possibiliclade de promoçào da gestão democrática dos serviços de saúde, com a busca de instrumentos/técnicas de planejamento participativo, com a articulaçào entre os saberes da Epidemiologia e do Planejamento - ressaltando-se aqui a preocupação com a necessidade de incorporação dos conteúdos da assim denominada Epidemiologia Social - e, ainda, com o desenvolvimento de metodologia de planejamento intersetorial e integrado.

Em termos das questões ou temas gerais que concentravam as discussões da área, é interessante observar que, naquele momento, ainda era objeto de debate, entre outras questòes, a "Delimitação dos Espaços do Planejamento e da Administração", a "Falsa Contradição entre Teoria e Prática" e "O Papel Político do Planejador".
A segunda metade da década de 80 traz um contexto bastante distinto para o desenvolvimento da área. A intensificação do movimento político pela Reforma Sanitária a partir da VIII CNS, tendo como perspectiva as lutas travadas na Assembléia Nacional Constituinte, além do avanço no processo de descentralizaçìo e unificação do Sistema de Saúde, com a proposta de implementação do SUDS, contextualizam uma situação mais favorável à aproximação da academia com os serviços de saúde, em termos de cooperação técnica, bem como contribuem para um crescimento relativo das atividades de investigação.

Neste contexto é que se realiza, em 1987, o Seminário "A Epidemiologia e o Planejamento na Unificação do Sistema de Saúde", reunindo profissionais da academia e dos serviços, quando sào discutidas entre os temas principais:

i) Concepções, obstáculos, avanços e propostas relativos à integração entre a Epidemiologia e o Planejamento nas práticas de saúde;

ii) A importância da POI — ProgramaçãoOrçamentaçào Integrada - como instrumento facilitador do uso da Epidemiologia no Planejamento e organizaçào dos serviços;

iii) A estrutura organizacional dos órgàos do SUDS;

iv) As estratégias de superação da baixa calpacidade de gasto do setor, e

v) As bases epidemiológicas para a estruturação de um sistema unificado de informaçào.

É interessante notar que, naquele momento, a perspectiva estratégica em planejamento já era bastante valorizada, assim como já se destacava o tema "gestão". Cabe ressaltar ainda que, durante esse período, a temática "Políticas de Saúcle" ganhou relevância no seio da ABRASCO, com a criação de uma comissão específica que teve papel destacado no processo de discussão do temário da VIII CNS e, posteriormente, no acompanhamento $e$ 
avaliação do processo de implementação do SUDS nos estados.

Já a partir de 1989, com o retrocesso político e suas repercussões no processo de Reforma Sanitária, observa-se a intensificação do debate em torno do desenvolvimento técnico-científico no campo da Saúde Coletiva, expressa nas iniciativas da área de Epidemiologia, e posteriormente das Ciências Sociais em Saúde, cujos desdobramentos incluíram a realização dos Congressos Brasileiros de Epidemiologia e, mais recentemente, já num contexto de intensificação do processo de Municipalização, do Encontro Nacional e do I Congresso de Ciências Sociais em Saúde.

Neste contexto mais recente, particularmente a partir de 1993, é que se verificam os movimentos de rearticulação da área de $P$ \& G (referidos no início deste artigo), culminando na realização, em 1995, da Oficina de São Paulo, que explicitou o fato de que nesta década e meia não só houve uma ampliação bastante significativa das temáticas da área e de seu grau de complexidade, como uma diversificação importante das atividades acadêmicas realizadas, com peso progressivamente maior para as atividades de pesquisa e cooperação. É o que veremos com maior detalhe no item subseqüente.

\section{2 - Situação atual da ârea de P \& G em Saúde}

O levantamento realizado junto aos núcleos institucionais, revelou a existência de uma concepção bastante ampliada (ou uma diversidade de possibilidades de recorte) dos objetos de saber/intervenção incluídos sob a denominação de "Administração e Planejamento em Saúde" ou "Planejamento e Gestão em Saúde". A sistematização das áreas temáticas a partir da identificação e classificação, por palavras-chave, das citações apontou, entretanto, diferentes ênfases, indicando uma certa tendência a privilegiar, neste campo, ques- tões relacionadas à gestão de sistemas e serviços, planejamento em saúde, em seus vários enfoques, avaliação em saúde e organização de sistemas e serviços (Anexo 3).

Assim, a primeira área temática, por ordem de citações, é a que se denominou GESTÃO EM SAÚDE, incluindo como sub-áreas "Gestão de Serviços e Sistemas de Saúde", "Gestão Hospitalar", "Gestão de Qualidade", "Gestão Estratégica" e "Gestão Orçamentária e Financeira". Como se pode observar, as subáreas apresentam diferentes graus de generalidade. É o caso, por exemplo, da sub-área "Gestão Hospitalar", que poderia ter sido incluída na de "Gestão de Serviços e Sistemas". Optou-se, entretanto, por mantê-las como duas sub-áreas separadas dada a especificidade e importância relativa do tema "gestão hospitalar" no conjunto dos temas relativos à gestão de serviços. O mesmo procedimento foi adotado com relação às sub-áreas "Gestão da Qualidade" e "Gestão Estratégica", cujo destaque pode ser justificado não apenas por seus "pesos relativos" em termos de citações, mas por representarem recortes temáticos $\mathrm{e}$ metodológicos relativamente novos em comparação aos demais.

A segunda área temática mais citada é a de PLANEJAMENTO EM SAÚDE, no âmbito da qual - e a despeito das diferenças ou identidades conceituais - foram agrupados os temas relativos à Programação em Saúde. Cabe observar que a primeira sub-área tem a mesma denominação da área, isto é, "Planejamento de/em Saúde", em virtude da forma genérica com que os núcleos referiam-se às temáticas trabalhadas. Por outro lado, dada a relativa importância assumida pelo enfoque estratégico no conjunto dos temas tratados nesta área temática, e por se constituir em um enfoque teórico-metodológico bem delimitado, optou-se por considerar o "Planejamento Estratégico" como uma sub-área específica.

A terceira área temática em ordem de citações é a de AVALIAÇĀO EM SAÚDE, na qual foram identificadas como sub-áreas a 
"Avaliação de Serviços" - denominação genérica, mas impossível de ser evitada dada a forma inespecífica das citações —, além de "Avaliação de Qualidade", "Avaliação de Tecnologias" e "Investigação em Serviços de Saúde". Com relação à "Avaliação de Qualidade", embora se possa considerar que este tema esteja inserido em "Avaliação de Serviços", optou-se por mantê-lo em destaque, enquanto sub-área, por representar uma temática nova em torno da qual registram-se esforços no sentido de construção de um enfoque teórico-metodológico específico no campo da avaliaçào.

A quarta área temática - SISTEMAS DE SAÚDE - abarca um conjunto de sub-áreas estreitamente relacionadas. Aí se incluem as sub-áreas "Organização de Serviços" e "Sistemas de Saúde" - denominaçôes igualmente genéricas, mas que apareceram em grande número de questionários -, ao lado de outras mais específicas como "Sistemas Locais de Saúde", "Modelos Assistenciais" e, ainda, "Vigilância da Saúde". Estas últimas, embora representando temas intimamente relacionados, foram mantidas em separado, como sub-áreas, por sugerirem distintas tendências, em termos de recortes teórico-metodológicos, no atual debate acadêmico e nos serviços, acerca das propostas de organização das práticas de saúde.

As demais áreas temáticas em ordem de citações são: RECURSOS HUMANOS EM SAÚDE, seguida por POLÍTICAS DE SAÚDE, INFORMAÇÃO EM SAÚDE e ECONOMIA EM SAÚDE. A área de "Recursos Humanos" compõe-se das subáreas - "Gestão de RH", "Formação e Capacitação" e "Processo de Trabatho em Saúde", esta última, inclusive, com uma interface com a sub-área de "Organização de Serviços de Saúde" e "Modelos Assistenciais", ambas incluidas na área "SISTEMAS DE SAÚDE". Por sua vez, a área de POLÍTICAS DE SAÚDE se subdivide em três subáreas, a primeira das quais leva o mesmo nome da área, sendo as outras sub-áreas: "Políticas Econômicas e Sociais" e "Controle Social".
$\mathrm{Na}$ área de INFORMAÇÕES EM SAÚDE, chama a atenção a indicação da sub-área "Informática Aplicada à Saúde", que não é específica do P \& G em Saúde. Dentro da sub-área "Sistemas de Informação", destaca-se o tema "Gerência de Sistemas de Informação", preocupação relativamente nova com referência ao enfoque tradicional, voltado apenas para o desenho de sistemas de informação, definição de indicadores etc.

A área ECONOMIA EM SAÚDE contém duas sub-áreas, a primeira, que leva o nome da área e uma segunda denominada "Financiamento". É interessante observar a imprecisão com que esta área é denominada (Economia da/em/e Saúde) pelos diversos núcleos, refletindo, provavelmente, diferentes concepções quanto às interrelações possíveis entre estes dois campos de conhecimento.

Considerou-se em separado, enquanto "temáticas emergentes", um conjunto de temas mencionados nas respostas ao questionário que se referem à problemática das relações entre comunicação e gestão/planejamento; às relações entre espaço, processos saúde/doença e oferta/organização de serviços de saúde; à complexidade das organizações de saúde e das possibilidades de mudança nestas organizações; bem como às temáticas relativas ao uso da Epidemiologia em serviços de saúde?.

Além dessas temáticas, que não são exclusivas da área de P \& G, mas que refletem a busca de um trabalho interdisciplinar no campo da Saúde Coletiva, chama a atenção a

s Ainda assim, cabe ressaltar que a maioria dos docentes da área estava inserida nos cursos de especializaçào em Saúde Pública e Residência em Medicina Preventiva e Social - ainda eram poucos os cursos específicos de aperfeiçoamento ou especialização na área o que parece em parte revelar o próprio estágio do desenvolvimento teórico-metodológico da área, em termos de um acúmulo ainda insuficiente de conhecimentos e técnicas específicos. 
emergência, no interior da área, de recortes temáticos relativamente novos, como por exemplo, "Gestão/Organização Tecnológica do Processo de Trabalho em Saúde", "Gestão da Qualidade", "Gestão Estratégica", "Avaliaçào/ Incorporação Tecnológica em Saúde", entre outras. Pode-se considerar que o destaque confericlo a essas temáticas na investigação e na intervenção em P \& G em Saúde indica o reconhecimento da especificidade das organizaçòes de saúde e da complexidade dos desafios que hoje se apresentam, nos planos teórico-metodológico e prático-instrumental, com relaçào ao planejamento e gestão do SUS.

Considerando a situação aqui apresentada, a proposta para denominação da área "Planejamento \& Gestão em Saúde" $"$ - em substituiçào a "Administração e Planejamento em Saúde", não só corresponde às áreas temáticas que concentram maior número de atividades, como indica um deslocamento das temáticas tradicionais da Administração e Planejamento para uma ênfase em abordagens mais abrangentes, que dêem conta tanto da complexidade do processo político no âmbito da Saúde quanto da especificidade das organizações de saúde e dos problemas gerenciais daí derivados.

\section{4 - Pesquisa, Ensino e Cooperação Técnica em P \& G: Tendências}

A identificação das atividades de pesquisa, ensino e cooperação técnica desenvolvidas pelos núcleos de P\&G permitiu analisar sua distribuição segundo a localização territorial/institucional, e segundo as áreas

\footnotetext{
${ }^{8}$ Poder-se-ia reproduzir aqui uma certa polêmica entre o nível de abrangência e os significados dos termos "Planejamento" e "Gestão", pensamos, porém, que este deva ser, inclusive, um dos objetos de reflexão, dentro do esforço de rearticulação da área.
}

temáticas apresentadas acima (neste último caso, ver Anexo 4). De um modo geral, identificou-se uma grande heterogeneidade na concentração das diversas atividades nos núcleos e áreas clistintas. As atividades de pesquisa encontram-se mais institucionalizadas nos núcleos maiores, especialmente na região Sudeste, enquanto que os núcleos das demais regiôes concentram a maior parte de suas atividades no ensino e na cooperação técnica, esta última atividade, aliás, presente em todos os núcleos.

\section{1 - Pesquisa}

Do total de 26 instituições que responderam ao questionário, 6 não referiram ativiclades de pesquisa em P \& G (DRH/SES-PA, NESC-RN, Universidade Estadual de Santa Cruz, Núcleo de Saúde/PUCAMP, Depto. Saúde Comunitária/UFPR e Universidade de Caxias do Sul). Entre as que mencionaram estas atividades, computou-se um total de 171 pesquisas em andamento, que não se distribuíam, obviamente, de forma homogênea entre as instituiçôes. Enquanto alguns núcleos reportam apenas uma ou duas pesquisas em andamento, instituições de grande porte e com tradição na área, como a ENSP e a USP, por exemplo, desenvolvem, respectivamente, de três a seis dezenas de pesquisas na área.

O eixo central da análise das atividades de pesquisa foi a sua distribuição por áreas temáticas. Procurou-se também avaliar a natureza dos estudos realizados (se estudos de caso, pesquisa operacional ou teórica, por exemplo). Não foi possível, no entanto, aprofundar este tipo de análise pois, pelas limitações do próprio instrumento de coleta, somente contamos com os títulos das pesquisas, que nem sempre são suficientes para permitir sua classificação nas sub-áreas temáticas, e raramente permitem alguma inferência sobre a metodologia adotada. 
No que se refere à distribuição por áreas temáticas (Anexo 4), o que se observa é que algumas áreas são mais concentradoras de atividades de pesquisa do que de docência ou cooperação. É o caso da área de Avaliação em Saíde, com $25 \%$ das pesquisas, assumindo o primeiro lugar enquanto concentradora deste tipo de atividade, ao passo que a área de Planejamento - segunda área temática mais citada - concentra apenas 7\% das pesquisas desenvolvidas.

Entre as pesquisas da área de Avaliação, destaca-se o peso da sub-área Avaliação de Qualidade. De fato, a temática da qualidade ganha relevo como concentradora de pesquisas, não só dentro da área de Avaliação em Saúde como também na área de Gestâo, dentro da sub-área Gestão de Qualidade. De certo modo, esta parece ser uma tendência atual no sentido de responder a demandas crescentes dos serviços por uma maior resolutividade, melhoria de seus produtos e aumento de sua capacidade de resposta aos problemas. Cabe registrar, no entanto, como uma das preocupações presentes nos debates da área (ABRASCO, 1994), a necessidade de se discutir mais profundamente a adequação de algumas abordagens, como a do Controle da Qualidade Total, à especificidade e complexidade das organizações e dos problemas de saúde.

Outra observação importante com relação às pesquisas realizadas na área de $A v a-$ liaçăo é que, aparentemente, em sua maior parte - considerando apenas os títulos das pesquisas como fonte de informação - estas se constituem em pesquisas descritivas ou estudos de caso. A se confirmar esta tendência, cabe questionar até que ponto estes estudos subsidiariam a reflexão/produção teórico-metodológica, e o conseqüente desenvolvimento de instrumental/tecnologias de avaliação.

Além da área de Avaliação, destacam-se, como principais concentradoras das atividades de pesquisa na área geral de P \& G, as áreas de Gestão, Sistemas de Saúde e Políticas de Sauide que, juntas, concentram $40 \%$ das pesquisas em desenvolvimento, com uma distribuição relativamente equilibrada do número de pesquisas entre si. Observa-se que as áreas de Gestão e de Políticas parecem igualmente concentrar um grande número de estudos de caso. Na área de Políticas, chama a atenção o fato de que, das 21 pesquisas identificadas, apenas uma refere, em seu título, a questão da Municipalização. Na área de Sistemas, o peso maior recai sobre as pesquisas voltadas para as questões relativas à Vigilância da Saúde.

A análise da situação da produção de pesquisas em $P$ \& $G$ em Saúde sugere algumas tendências interessantes. Tomando como referência apenas o levantamento realizado em 1982 pela ABRASCO (Temporão \& Rivera, 1983), pode-se dizer que nos últimos 14 anos a produção de pesquisas na área experimentou um incremento extraordinário, observando-se, além de um significativo aumento no número de pesquisas, uma diversificação bastante importante das temáticas tomadas como objeto de investigação. Esta diversidade temática (ou tendência à especialização crescente ?) explicaria, pelo menos parcialmente, o esvaziamento da temática "Planejamento em saúde" propriamente dita como objeto de investigação. Por outro lado, obervase também uma maior ênfase na gestão como temática de investigação, sugerindo talvez um deslocamento do objeto de trabalho do Planejamento para o interior das organizações. Finalmente, cabe registrar o pequeno número de pesquisas, aparentemente, voltadas para a reflexão epistemológica e a investigação teórico-metodológica na área. Discutir tais tendências e suas implicações para o desenvolvimento teórico-metodológico do P \& G em Saúde, bem como para sua capacidade de resposta aos problemas atuais e potenciais da realidade sanitária e do setor saúde do país, é uma das tarefas prioritárias neste momento de rearticulação da área. 


\section{2 - Ensino de Graduação}

O primeiro aspecto que chama a atenção ao analisarmos as informações referentes ao ensino de Graduaçào é o fato de que pouco menos da metade dos núcleos atuam nesse nível de formação, especialmente os que são vinculados a universidades. Dos 40 núcleos que responderam ao questionário, 21 não referiram atividades em graduação: o DRH/ SES/Pará; quatro núcleos vinculados à Escola de Saúde Pública de Minas Gerais; sete vinculados à ENSP/FIOCRUZ; além do PROHASA/FGV; FUNDAP; Instituto de Saúde da SES/SP (4 núcleos); o CELAG/DMS/ $\mathrm{St}^{\mathrm{a}}$ Casa-SP; o núcleo de Saúde da PUC/Campinas e a Escola de Saúde Pública do Rio Grande do Sul.

Esses dados certamente não refletem a realidade do ensino de Planejamento \& Gestão nos cursos de graduação da área de saúde. O viés introduzido pelo fato de se ter encaminhado o questionário a todos os núcleos institucionais que desenvolvem cursos de pós-graduação se, por um lado, incluiu instituiçôes não universitárias, por outro, excluiu um conjunto significativo de faculdades e escolas que atuam basicamente na graduação, como grande parte das escolas de Medicina e Enfermagem que, por força das normas que definem o currículo mínimo, seguramente desenvolvem atividades de ensino neste campo.

Tomando, portanto, as informações relativas ao ensino de graduação como um recorte bastante pequeno (18 núcleos que referiram atuar em graduação), chama a atenção o fato da maioria (14) indicar participação em cursos de Medicina, seguido de Enfermagem (6) e Nutrição (3). Apenas três núcleos mencionaram uma atuação ampliada ao nível da graduação, envolvendo Medicina, Enfermagem, Odontologia, Nutrição, Farmácia e/ou Medicina Veterinária: o ISC da Universidade Federal Fluminense; o NESCO-Londrina e o ISC/UFBa, ainda em processo de articulação desta atividade integrada.
A explicação para este quadro encontrase no fato de a grande maioria dos núcleos universitários incluídos no levantamento serem vinculados a Departamentos de Medicina Preventiva e Social das Escolas de Medicina, espaço onde se originaram os cursos de pósgraduação que integram o campo de abrangência da ABRASCO.

Quanto ao conteúdo do ensino, levando em conta para efeito de análise as denominações das disciplinas oferecidas, chama a atenção o fato da grande maioria ter denominaçôes genéricas, como "Administração em Saúde Pública", "Administração em Serviços de Saúde", "Políticas de Saúde", "Políticas e Planejamento de Saúde", "Planejamento e Gerência de Serviços de Saúde", "Organização e Administração de Saúde", "Planejamento e Programação de Saúde". Muitas disciplinas incluem o termo "Introdução" em sua denominação: "Introdução à Saúde Coletiva", "Introdução à Saúde Pública", "Introdução à Medicina Preventiva". Apenas a Faculdade de Saúde Pública da USP refere uma disciplina de "Administração Hospitalar" (para o curso de Nutrição), e apenas o Departamento de Medicina Preventiva da UFPe registra uma disciplina chamada "Economia e Administração" (de empresas farmacêuticas).

Ainda que não se possa, com esses clados, proceder a uma análise aprofundada, pode-se levantar a hipótese de que o ensino do Planejamento \& Gestão em Saúde na graduação é geral e inespecífico, de caráter basicamente informativo, limitando-se a grandes temas relacionados às áreas temáticas "Gestão de Sistema de Saúde" e "Políticas e Planejamento de Saúde". Somente através de um estudo dos programas das disciplinas seria possivel identificar o enfoque e a abrangência com que estas temáticas são tratadas. De todo modo, o alcance e a profundidade do ensino de $P$ \& G em Saúde na graduação é um ponto que merece um aprofundamento, considerando-se a necessidade de ampliação e fortalecimento desta área no processo de formação dos profissionais de saúde. 


\section{3 - Ensino de Pós-Graduação}

A análise dos dados relativos ao ensino do $P$ \& $G$ na pós-graduação revela, em primeiro lugar, a diversidade de cursos de especializaçào senso lato. Assim, ao lado dos cursos de PG senso estrito - Mestrado (14) e Doutorado (5) - aparecem os cursos de Especialização em Saúde Pública (8), as Residências em Saúde Pública ou Medicina Preventiva e Social (6), e vários cursos de especialização com conteúdo específico, como "Gerência de Unidades", "Administração em Serviços de Saúde", "Gestão de RH", "Desenvolvimento Gerencial", "Administração Hospitalar", "Recursos Humanos em Saúde", "Vigilância Sanitária de Produtos e Serviços", "Administração e Planejamento de Serviços Públicos de Saúde", "Administração em Serviços de Saúde com ênfase em Administração Hospitalar", "Planejamento e Gerenciamento em Saúde", "Gestão de Sistemas de Saúde", "Planejamento, Programação e Gestão em Saúde".

Além disso, mencionam-se vários cursos de aperfeiçoamento/atualização em temáticas específicas como "Epidemiologia em SILOS", "Planejamento Estratégico e Gestão Comunicativa", "Gerência de Serviços de Saúde", "Gerência em Vigilância Sanitária de Serviços de Saúde", "Custos Hospitalares", "Gestão Estratégica e Organização de Serviços de Saúde", "Finanças Públicas" etc.

A análise da distribuição das atividades de ensino de Pós-Graduação por área temática (Anexo 4) aponta que as áreas de Gestâo em Saide e Planejamento em Saide concentram quase $60 \%$ das citações (palavras-chave incluídas na denominação das disciplinas e cursos), com $28 \%$ na área de Gestão e 30\% na área de Planejamento.

Chama a atenção o fato de que, na área de Gestâo, a única sub-área citada além da subárea de Gestão de Serviços e Sistemas é a de Gestão Hospitalar, concentrando $10 \%$ das referências de atividades de ensino. Isto não significa, necessariamente, que as demais sub- áreas temáticas não sejam tratadas nos cursos e disciplinas da área. O mesmo cabe observar quanto às citações nas sub-áreas de Planejamento em Saíde, que provavelmente não refletem o real peso dos conteúdos de planejamento estratégico e programação nas disciplinas e cursos, já que estes, em geral, vêm denominados apenas como "Planejamento em Saúde". Em seguida, aparecem as áreas de Politicas de Saíde (12\%) e Recursos Humanos em Saúde (9\%), sendo que as demais áreas, como Avaliação, Informação, Economia e Sistemas de Sauide comparecem com percentuais bem menores, variando de 4 a $6 \%$.

Com base nestas informações, podemos constatar que os cursos e disciplinas seguem, via de regra, a hierarquização das áreas temáticas, com ênfase nas áreas de Gestão, Planejamento, Políticas de Saúde, Recursos Humanos em Saúde, seguidas das demais áreas. Provavelmente, vem crescendo o interesse em incluir temáticas como Avaliação, Informação, Economia em Saúde, além de aspectos organizacionais e operativos de sistemas de saúde, no âmbito das disciplinas e cursos, porém este interesse ainda não se reflete na criação de cursos específicos, na grande maioria dos núcleos.

Os núcleos da região Sudeste são os que apresentam uma tendência mais acentuada em diversificar o leque de opções dos cursos de especialização, atualização e aperfeiçoamento, provavelmente, atendendo a uma tendência de aprofundamento em temáticas que se tornam cada vez mais necessárias ao desenvolvimento do sistema de saúde e à diversificação do quadro de docentes/pesquisadores, dado o maior contingente de pessoal envolvido nas atividades destes núcleos.

\section{4 - Cooperação Técnica}

O levantamento dos projetos e atividades de cooperação técnica referidas pelos núcleos indica a existência de três tipos de ativida- 
des: cursos de extensão, geralmente oferecidos por instituições universitárias, assessorias/consultorias a instituições de serviços, em nível federal, estadual e, principalmente, local; além da prestação direta de serviços através de unidades vinculadas à estrutura acadêmica, como é o caso dos Centros de Saúde-Escola.

A grande maioria dos núcleos desenvolve cursos e atividades de assessoria. Três deles - o DMP/FM/USP, o DMS/FM-Ribeirão Preto/USP e o Núcleo de Planejamento Estratégico/DAPS/ENSP incluem, entre suas atividades de cooperação, assessorias aos centros de saúde-escola de suas próprias instituições.

Os cursos de extensão, por sua vez, estão voltados, basicamente, para a capacitação de pessoal de seviços de saúde. Aparecem, contudo, duas referências à capacitação de conselheiros municipais de saúde. As áreas temáticas em que predominam os cursos não diferem das áreas principais identificadas no campo, quais sejam: gerência de unidades, inclusive hospitalares; planejamento e programação; avaliação de serviços e desenvolvimento de recursos humanos, incluindo análises do processo de trabalho em saúde.

Já as atividades de assessoria/consultoria apresentam duas características interessantes. De um lado, o desenvolvimento de projetos de cooperação técnica internacional, geralmente nas instituições de grande porte, como a ENSP, a FSP/USP, e, em menor escala, o ISC/ UFBa, sendo que algumas, como o PROHASA e o IES/SP, desenvolvem projetos de cooperação interestadual. A grande maioria dos núcleos, entretanto, trabalha em nível municipal e intermunicipal, atuando ou no município onde se localiza o núcleo ou em outros municípios do mesmo estado.

As indicações relativas ao conteúdo das atividades revelam uma prioridade em Gestão, compreendendo gestão de serviços, gestão hospitalar, desenvolvimento gerencial-organizacional das estruturas político-administrativas, especialmente Secretarias Municipais de Saúde, gestão de recursos e introdução de critérios de qualidade na organização e gerência de sistemas e serviços. Em segundo lugar, aparece o apoio à capacitação de $R e$ cursos Humanos, seguidas imediatamente pelas atividades de cooperação na área de Planejamento em Saúde, particularmente as ativiclades de assessoria/consultoria para a execução dos processos de planejamento e programação em saúde em nível municipal e local. Em quarto lugar, aparece a área de Sistemas de Sailde, onde se destacam as subáreas de Organização de Serviços e Vigilância da Saúde. Em quinto lugar, aparecem as atividades de Avaliaçấo em Sañde, Políticas e Informação em Sanide, especialmente as de apoio técnico ao desenvolvimento de Sistemas de Informação.

A tendência observada no sentido da ampliação das atividades de cooperação junto ao nível local certamente reflete o crescimento da demanda por serviços de cooperação técnica por parte das prefeituras municipais e serviços locais, em função do processo de descentralização da gestão do sistema de saúde.

A despeito do significativo incremento desse tipo de atividade em comparação ao que se verificava no início dos anos 80 (Temporão \& Rivera, 1983 e ABRASCO, 1983), não se pode avaliar, com os dados disponíveis, até que ponto está ocorrendo uma institucionalização dessas atividades - através de convênios ou contratos de prestação de serviços -, o que refletiria o estabelecimentos de compromissos interinstitucionais mais permanentes e voltados para objetivos estratégicos do setor, ou se estas atividades dependem, ainda e principalmente, de iniciativas individuais dos docentes/pesquisadores dos núcleos e dos profissionais dos serviços.

\section{5 - Desafios e Perspectivas para a Área de P \& G em Saúde}

O desenvolvimento científico e tecnológico da Saúde Coletiva e o desafio de fazer 
avançar o processo de reforma do sistema de saúde brasileiro, formula uma série de desafios para área de Planejamento e Gestão em Saúde. Nas reuniões específicas realizadas nos últimos anos, vários desses desafios vêm sendo explicitados, enfatizando-se, inclusive, a necessidade de se promover a rearticulação política dos núcleos institucionais da área.

Em linhas gerais, constata-se nestes encontros a significativa "fragilidade das bases político-institucionais e metodológicas dos processo de planejamento e gestão no âmbito do SUS" (MS/ABRASCO, 1993). Nesse sentido, tem sido ressaltada a dificuldade de fortalecer os processo de planejamento e gestão em uma situação de esvaziamento do movimento político mais amplo pela Reforma Sanitária e de extremo sucateamento dos serviços públicos de saúde, precariedade de infra-estrutura, baixa remuneração dos profissionais e insuficiente qualificação de grande parte dos mesmos (ABRASCO, 1994).

Do ponto de vista da gestão do sistema de saúde, o que se observa é que Estados e Municípios se encontram em niveis diferenciados, tanto com relação à autonomia e capacidade gerencial, como em relação ao próprio modelo de gestão (ABRASCO,1994). Alguns problemas que se verificam no processo de construção do novo modelo de gestão do SUS dizem respeito: à (re) centralização dos processos de gestão das instituições de saúde, em função dos mecanismos de repasse de recursos financeiros; à insuficiente capacidade de gestão das relações público/privado; à diversidade de modalidades de gestão que têm sido desenvolvidas na esteira da descentralização, carecendo-se de uma avaliação mais rigorosa de suas implicações para a qualidade das ações de saúde prestadas, bem como para o cumprimento dos princípios essenciais do SUS.

Com relação ao planejamento setorial destacam-se entre os principais problemas: a dissociação entre o processo de planejamento - praticamente restrito ao formalismo pro- cessual - e o efetivo processo de tomada de decisões sobre as políticas de saúde; a redução do planejamento a um instrumento de captação de recursos, utilizado em momentos pontuais da vida institucional; a incipiente participação da sociedade civil e dos profissionais de saúde em geral nos processos de planejamento (MS/ABRASCO, 1993).

Outro problema que vem sendo ressaltado é o não desenvolvimento de esforços sistemáticos visando a análise crítica e a avaliação das possibilidades de articulação das diversas abordagens teórico-metodológicas adotadas na área de P \& G em Saúde. Embora tenham sido produzidos, no âmbito acadêmico, particularmente nos últimos anos, trabalhos relevantes de reflexão crítica sobre o Planejamento em Saúde, reconhece-se que a reflexão e o debate sobre alternativas de gestão e organização de sistemas e serviços de saúde ainda são insuficientes.

Além disso, aponta-se a necessidade de uma avaliação das implicações dos princípios do SUS para o aperfeiçoamento dos instrumentos de planejamento e gestão, bem como um estudo mais sistemático dos aspectos metodológicos das experiências inovadoras de planejamento e gestão em curso, especialmente no que se refere à potência dessas metodologias e sua capacidade de contribuição para a transformação da organização dos serviços e das práticas de saúde (ABRASCO, 1994).

O esvaziamento da capacidade gerencial não só dos Estados e Municípios, mas do próprio nível federal, é um dos problemas centrais com que se defronta o processo de construção do SUS no momento atual (Levcovitz, 1995), agravado pela escassez de recursos financeiros e a conseqüente necessidade de racionalização, além da difusão e experimentação de opções de corte neoliberal, que não contemplam a necessidade de se promover uma ampla e profunda reforma no modelo assistencial com base nos princípios da universalidade, eqüidade e integralidade das ações. 
A despeito da existência de debate acadêmico sobre modelos assistenciais e dos avanços que vêm se verificando no interior de algumas experiências inovadoras no âmbito da reorganização dos serviços, não contamos ainda com uma discussão sistemática das estratégias político-institucionais e dos desafios técnico-científicos e políticos, de modo a imprimir uma direcionalidade ao SUS que ultrapasse os marcos de um "SUS para pobres"'.

Algumas reflexões, entretanto, vêm ocorrendo tanto nos encontros, seminários e congressos da área de Saúde Coletiva, quanto nos encontros promovidos pelo MS, CONASS e CONASEMS, sem que se tenha ainda um mapeamento do conjunto desta problemática, suas tendências e perspectivas.

Do ponto de vista teórico-conceitual e metodológico, o debate tem refletido a diversidade de concepções em torno de algumas questões relevantes, como por exemplo, a questão do objeto, métodos, técnicas e instrumentos de trabalho do Planejamento \& Gestão em Saúde, demandando um aprofundamento no plano epistemológico que permita uma delimitação mais precisa da abrangência da área e uma avaliação de seus métodos e técnicas, no sentido de examinar sua adequação à complexidade dos problemas de saúde e das organizaçôes do setor.

Do ponto de vista político-institucional e operativo, o debate vem destacando a importância de se avançar nas investigações e proposições sobre os modelos e práticas alternativas de planejamento e gestão nos vários níveis do Sistema. Além disso, vem sendo enfatizada uma temática que já havia sido tratada nos anos 80, qual seja, a necessidade de incorporaçào do enfoque epidemiológico no Planejamento \& Gestão em Saúde, como meio para o desenvolvimento de novos Mo-

\footnotetext{
"Expressão utilizada no relatório da Oficina de Trabalho "Redefinição de Papéis, Reorganização Institucional ..." op. cit.
}

delos Assistenciais que levem em conta a especificidade das condições de vida e saúde das populações.

$\mathrm{Na}$ Oficina para a Rearticulação da Área, realizada em outubro de 1995, algumas destas questões foram retomadas e desenvolvidas, tendo sido ressaltados, por exemplo, alguns desafios políticos do processo de construção do SUS e a necessidade de rearticulação dos sujeitos da Reforma Sanitária Brasileira (Cecílio, 1995), os problemas e desafios político-institucionais gerados no processo de descentralização da gestão, especialmente após a NOB 001/93 (Levcovitz, 1995), além de algumas perspectivas teórico-metodológicas do campo, exemplificadas através de um contraponto entre o Planejamento Estratégico-Situacional e a Gestão da Qualidade, referidos ao contexto atual de problematização das relações entre o mercado e as políticas sociais (Rivera, 1995).

O debate acerca das estratégias de rearticulação da área apontou também para a necessidade de resgatar as experiências inovadoras em curso, mapeando as questões organizacionais, metodológicas, técnicas e instrumentais que vêm sendo postas pela prática. A expectativa é de que se constitua um espaço de intercâmbio e de amadurecimento da reflexão crítica e política, subsidiando-se assim a seleção de alternativas para a Área e a identificação dos obstáculos a serem superados para sua concretização.

Nesse sentido, defendeu-se, entre outras propostas, a idéia de formular uma agenda de prioridades para o desenvolvimento das pesquisas na Área, fomentando-se, inclusive, o fortalecimento de núcleos institucionais fora do eixo Rio-São Paulo, onde atualmente concentra-se a maior parte dos projetos em curso. Com relação ao Ensino, formularam-se proposições gerais que revelam a necessidade de aprofundar a análise das tendências atuais, inclusive para que se possa identificar áreas críticas que precisam ser priorizadas em 
função do desenvolvimento da capacidade gerencial dos sistemas locais de saúde, como, por exemplo, a gestão hospitalar, a gerência financeira, a gerência de pessoal, a avaliação de sistemas e serviços etc. Finalmente, com relação à cooperação técnica interinstitucional, campo de articulação da academia com os sistemas e serviços, foram estabelecidas algumas bases, de modo a que se desenvolva o intercâmbio e a articulação dos docentes e pesquisadores que se dedicam a esta atividade, como forma, inclusive, de fomentar um futuro programa de cooperação técnica com o Ministério da Saúde, o CONASS e o CONASEMS.

\section{6 - Considerações Finais}

O propósito central do movimento atual de rearticulação político-institucional da Área de P \& G, no âmbito acadêmico, é ampliar o processo de discussão em torno de seus problemas e perspectivas teórico-metodológicas, bem como possibilitar a definição das estratégias institucionais para a superação das dificuldades e obstáculos no âmbito da Pesquisa, do Ensino e da Cooperação técnica nesta área, tendo como referência o processo de construção do SUS.

Esperamos que a análise da situação atual, brevemente sumarizada neste artigo, seja um estímulo à reflexão e ao debate nos diversos núcleos acadêmicos, visando a um aprofundamento e a uma melhor compreensão da dinâmica do desenvolvimento científico e técnico da Área, bem como subsidiando a elaboraçào de propostas em torno do fortalecimento e aperfeiçoamento das atividades de Pesquisa, Ensino e Cooperação.

Nesse sentido, durante a Oficina para a Rearticulação da Área, já mencionada, formalizou-se a proposta de trabalhar na elaboração de um Plano Diretor para o P \& G em Saúde, tendo como ponto de partida as propostas e recomendações emanadas dos grupos de discussão e da plenária final daquele evento. A versão preliminar deste Plano Diretor é, portanto, o relatório final da Oficina que, correlacionando problemas e propostas, intitula-se Subsídios à Elaboração do Plano Diretor para a Área de Planejamento e Gestão em Saúde. Este documento deverá ser divulgado, de forma a mais ampla possível, junto aos núcleos acadêmicos e às instâncias representativas dos dirigentes políticos e trabalhadores de saúde que atuam na área de gestão e planejamento do SUS. Simultaneamente, constituíram-se grupos de trabalho com o propósito de aperfeiçoar as propostas e estratégias relativas à Pesquisa, ao Ensino e à Cooperação Técnica na área, esperando-se, com isso, ampliar e consolidar esse debate durante o Encontro Nacional de Planejamento \& Gestão em Saúde, previsto para novembro de 1996.

\section{Referências bibliográficas}

ABRASCO (1983) - I Reunião Nacional sobre Ensino e Pesquisa em Administraçào e Planejamento em Saúde na Área da Saúde Coletiva. Relatório final. In: ABRASCO - Ensino da Salide Príblica, Medicina Preventiva e Social no Brasil, Vol. II, p. 165-181, Rio de Janeiro.

(1983) - Seminário: "A Epidemiologia e o Planejamento na Unificação do Sistema de Saúde no Brasil", Águas de Lindóia. Relatório final, mimeo. (1984) - Curso de atualização para docentes e pesquisadores em Planejamento de Saúde. Relatório final. In: ABRASCO - Ensino da Saúde Pīblica, Medicina Preventiva e Social no Brasil, Vol. III, p. 161-167, Rio de Janeiro. (1994) - Oficina: "Redefinição de Papéis, Reorganização Institucional e Planejamento no 
Sistema de Saúde: Novos Desafios". Relatório final, IV Congresso Brasileiro de Saúde Coletiva, Recife.

CECíliO, L.C.O. (1995) - Planejamento em Saúde: Possibilidades e Limites enquanto Apoio ao Processo de Implementação do SUS. Exposição em Mesaredonda na Oficina de trabalho para a "Rearticulação da Área de Planejamento e Administraçào em Saúde no País". FSP/USP, São Paulo, mimeo.

LEVCOVITZ, E. (1995) - Exposição em Mesaredonda na Oficina de trabalho para a "Rearticulação da Área de Planejamento e Administração em Saúde no País". FSP/USP, Sào Paulo (transcriçào de fita).

MS/ABRASCO (1993) - Seminário: "O Processo de Planejamento na Construçào do SUS”, Brasília. Relatório final, mimeo.

OPS/OMS (1965) - Programación de la Salud: problemas conceptuales y metodológicos. Publicación Cientifica $\mathrm{n}^{\circ}$ 111. Washington, D.C.: OPAS,.

PAIM, J.S. (1983) - O movimento pelo planeja- mento de saúde na América Latina. Revista Baiana de Salide Píblica 10(1):46-52.

RIVERA, F.J.U. (1989) - Planejamento e programaçào em saúde: um enfoque estratégico. Sào Paulo: Cortez/ABRASCO.

(1995) - Exposição em Mesa-redonda na Oficina de trabalho para a "Rearticulação da Área de Planejamento e Administraçào em Saúde no País". FSP/USP, Sào Paulo (transcrição de fita).

TEIXEIRA, S.F. (1988) - O dilema da Reforma Sanitária brasileira. In: Teixeira, S. F. (org.) - Reforma Sanitária: Itália e Brasil. Sào Paulo: Hucitec/CEBES.

TEMPORÃO, J.G. \& RIVERA, F.J.U. (1983) Caracterizaçào do ensino e dos docentes em Administraçào e Planejamento em Saúde no Brasil. In: ABRASCO - Ensino da Salide Plíblica, Medicina Preventiva e Social no Brasil, Vol. II, p. 81-97, Rio de Janeiro. 


\section{Relação das Instituiçōes/Núcleos que Responderam ao Questionário}

1) Secretaria de Estado de Saúde Pública do Pará

2) Universidade Federal do Rio Grande do Norte 2.1 Núcleo de Estudos de Saúde Coletiva do Rio Grande do Norte

3) Universidade Federal da Paraiba 3.1 Centro de Ciências da Saúde/Núcleo de Estudos em Saúde Coletiva

4) Universidade Federal de Pernambuco 4.1 Centro de Ciências da Saúde/Departamento de Medicina Social

5) Universidade de Pernambuco

5.1 Faculdade de Ciências Médicas/Departamento de Medicina Preventiva e Social

6) Universidade Federal da Bahia

6.1 Instituto de Saúde Coletiva

7) Universidade Estadual de Santa Cruz, Ilhéus, BA

8) Universidade Federal de Minas Gerais

8.1 Faculdade de Medicina/Departamento de Medicina Preventiva e Social

9) Escola de Saúde de Minas Gerais/Fundação Ezequiel Dias

10) Universidade Federal de Viçosa, MG

11) Universidade do Estado do Rio de Janeiro 11.1 Instituto de Medicina Social

12) Fundação Oswaldo Cruz/Escola Nacional de Saúde Pública/Departamento de Administração e Planejamento em Saúde

12.1 Núcleo de Planejamento Estratégico em Saúde

12.2 Núcleo de Administração de Serviços de Saúde

12.3 Núcleo de Estudos e Pesquisas em Recursos Humanos

12.4 Núcleo de Avaliação da Atenção Médica e Tecnologias em Saúde

12.5 Núcleo de Estudos em Economia e Saúde

12.6 Grupo de Estudos em Qualidade da Administração Pública

12.7 Núcleo de Estudos Político-Sociais em Saúde

13) Universidade Federal Fluminense

13.1 Instituto de Saúde da Comunidade

14) Fundação Getúlio Vargas

14.1 Programa de Estudos Avançados em Administração Hospitalar e Sistemas de Saúde (PROAHSA)/Escola de Administração de Empresas de São Paulo
15) Fundação do Desenvolvimento Administrativo FUNDAP

16) Universidade de São Paulo:

16.1 Faculdade de Saúde Pública

16.2 Faculdade de Medicina/Departamento de Medicina Preventiva

16.3 Faculdade de Medicina de Ribeirão

Preto/Departamento de Med. Social

17) Instituto de Saúde de S. Paulo

17.1 Núcleo de Políticas Públicas em Saúde

17.2 Núcleo de Investigação de Sistemas de Saúde

17.3 Núcleo de Investigação em Educação em Saúde

17.4 Núcleo de Investigação em Saúde da Mulher e da Criança

18) Santa Casa de São Paulo

18.1 Departamento de Medicina Social/Centro de Estudos Augusto Leopoldo Ayrosa Galvāo

19) Pontificia Universidade Católica de Campinas 19.1 Núcleo de Saúde

20) Universidade de Campinas

12.1 Faculdade de Ciências Médicas/ Departamento de Medicina Preventiva e Social/Laboratório de Planejamento e Administração (LAPA)

21) Universidade Estadual Paulisto 21.1 Faculdade Medicina de Botucatu

22) Universidade Federal do Paraná 22.1 Departamento de Saúde Comunitária

23) Universidade Estadual de Londrina NESCO

23. I Núcleo de Estudos em Saúde Coletiva -

24) Secretaria de Saúde e Meio Ambiente de Porto Alegre

24.1 Escola de Saúde Pública

25) Universidade Federal do Rio Grande do Sul 25.1 Departamento de Medicina Social 25.2 Programa de Desenvolvimento de Gestāo e Administração

26) Universidade de Caxias do Sul, RS 


\section{Anexo 2}

Distribuição das Instituições, Núcleos e Pesquisadores/Docentes na Área de Planejamento \& Gestão em Saúde, por Região, Estado e Cidade do Brasil*

\begin{tabular}{lccccc}
\hline Região & Estados & Cidades & Instituiçס̃es & Núcleos & Pesq./Doc. \\
\hline Norte & 1 & 1 & 1 & 1 & 1 \\
Nordeste & 4 & 5 & 6 & 6 & 57 \\
Sudeste & 3 & 8 & 14 & 27 & 226 \\
C. Oeste & - & - & - & - & - \\
Sul & 2 & 4 & 5 & 6 & 45 \\
\hline Total & 10 & 18 & 26 & 40 & 329 \\
\hline
\end{tabular}

(*) Os dados referem-se apenas às instituiçōes, núcleos e pesquisadores/docentes que responderam ao questipnário enviado pela ABRASCO.

Anexo 3

Agrupamento por Áreas Temáticas, Sub-áreas e Temas, a partir do Agrupamento Preliminar das Citações por Palavras-chave

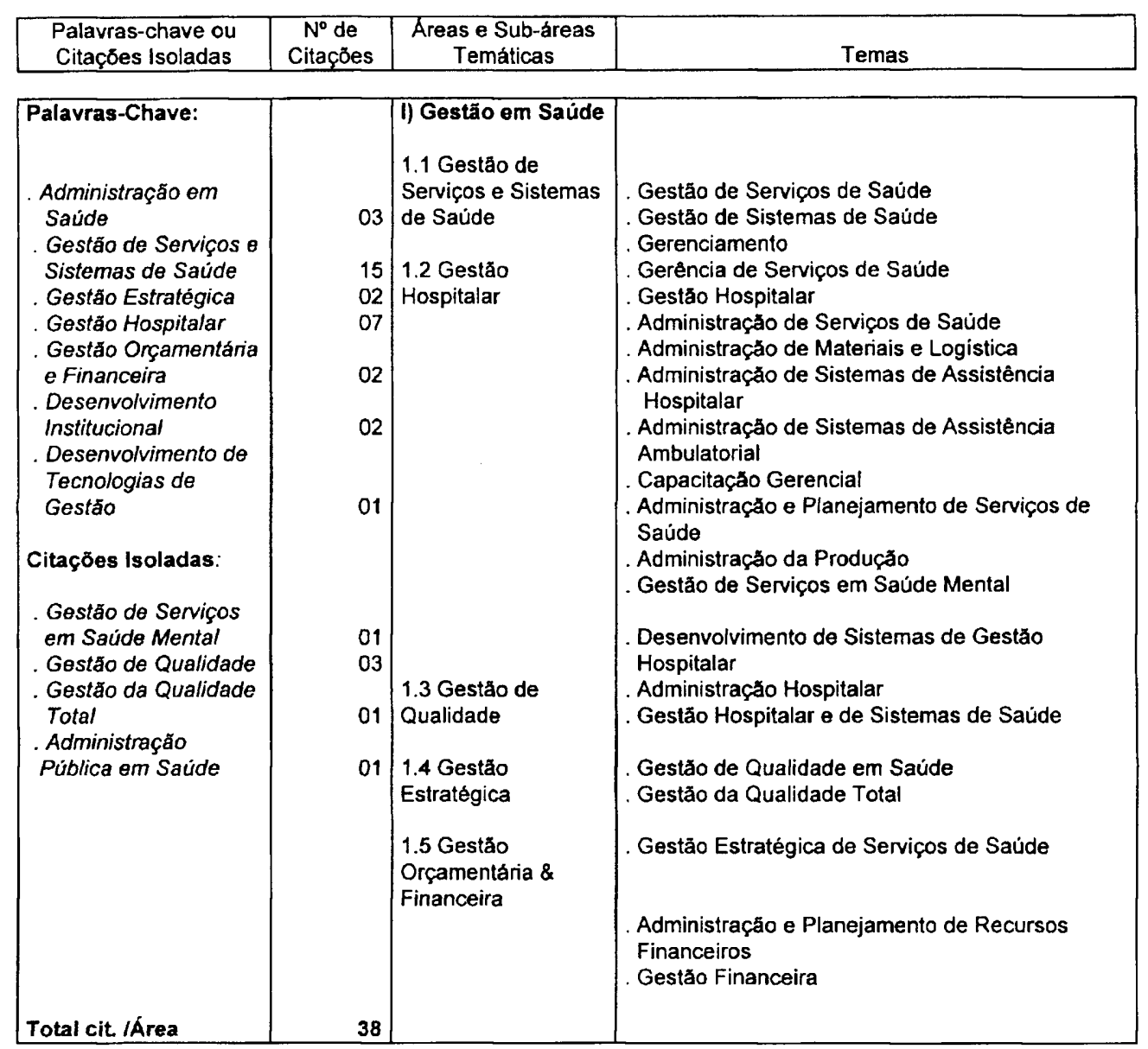




\begin{tabular}{|c|c|c|c|}
\hline $\begin{array}{l}\text { Palavras-chave: } \\
\text { planejamento } \\
\text { ascendente } \\
\text { planejamento em } \\
\text { saúde } \\
\text {. planejamento } \\
\text { estratégico } \\
\text {. programação em } \\
\text { saúde } \\
\text { gestão de projetos } \\
\text { Citaçōes isoladas: } \\
\text { Epidemiologia } \\
\text { aplicada a Planos de } \\
\text { Saúde } \\
\text { Análise da Situação } \\
\text { de Saúde }\end{array}$ & $\begin{array}{l}01 \\
13 \\
10 \\
05 \\
03\end{array}$ & $\begin{array}{l}\text { II) Planejamento em } \\
\text { Saúde } \\
\text { 2.1 Planejamento de } \\
\text { Saúde } \\
\text { 2.2 Planejamento } \\
\text { Estratégico } \\
\text { 2.3 Programação em } \\
\text { Saúde }\end{array}$ & 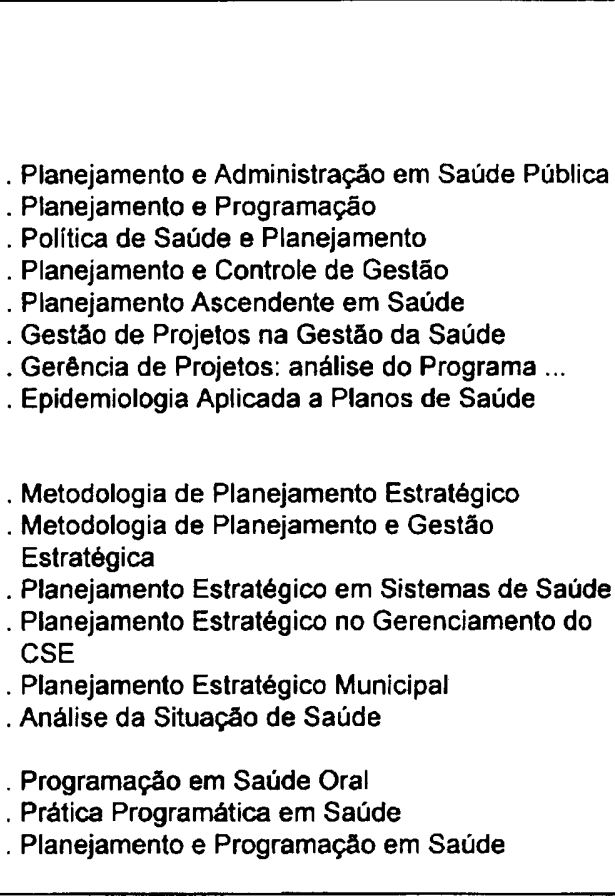 \\
\hline
\end{tabular}

\begin{tabular}{|c|c|c|c|}
\hline $\begin{array}{l}\text { Palavras-chave: } \\
\text { Avaliação de } \\
\text { Qualidade } \\
\text { Avaliação de } \\
\text { Serviços } \\
\text {. Avaliação de } \\
\text { Sistemas } \\
\text {. Avaliação de } \\
\text { Tecnologias } \\
\text { Investigação em } \\
\text { Serviços } \\
\text {. Assisténcia Médico- } \\
\text { Hospitalar } \\
\text { Qualidade em Saúde } \\
\end{array}$ & $\begin{array}{l}01 \\
04 \\
02 \\
01 \\
04\end{array}$ & $\begin{array}{l}\text { III) Avaliação em } \\
\text { Saúde } \\
\text { 3.1 Avaliação } \\
\text { de Serviços } \\
\text { 3.2 Avaliação } \\
\text { de Qualidade } \\
\text { 3.3 Avaliaçăo } \\
\text { de Tecnologias } \\
\text { 3.4 Investigação } \\
\text { em Serviços de } \\
\text { Saúde }\end{array}$ & $\begin{array}{l}\text { Avaliaçăo de Politicas e Serviços de Saúde } \\
\text {. Avaliaçăo de Serviços e Programas } \\
\text {. Avaliaçăo de Açס̃es e de Serviços de Saúde } \\
\text { Avaliaçăo de Serviços e Tecnologias em Saúde } \\
\text { (em interface com a Epidemiologia) } \\
\text {. . . dos serviços } \\
\text {. ... de sistemas } \\
\text {. ... da assistência à saúde } \\
\text {. qualidade em saúde } \\
\text {. Incorporaçăo de Tecnologia Médica em Saúde } \\
\text { Idem }\end{array}$ \\
\hline
\end{tabular}




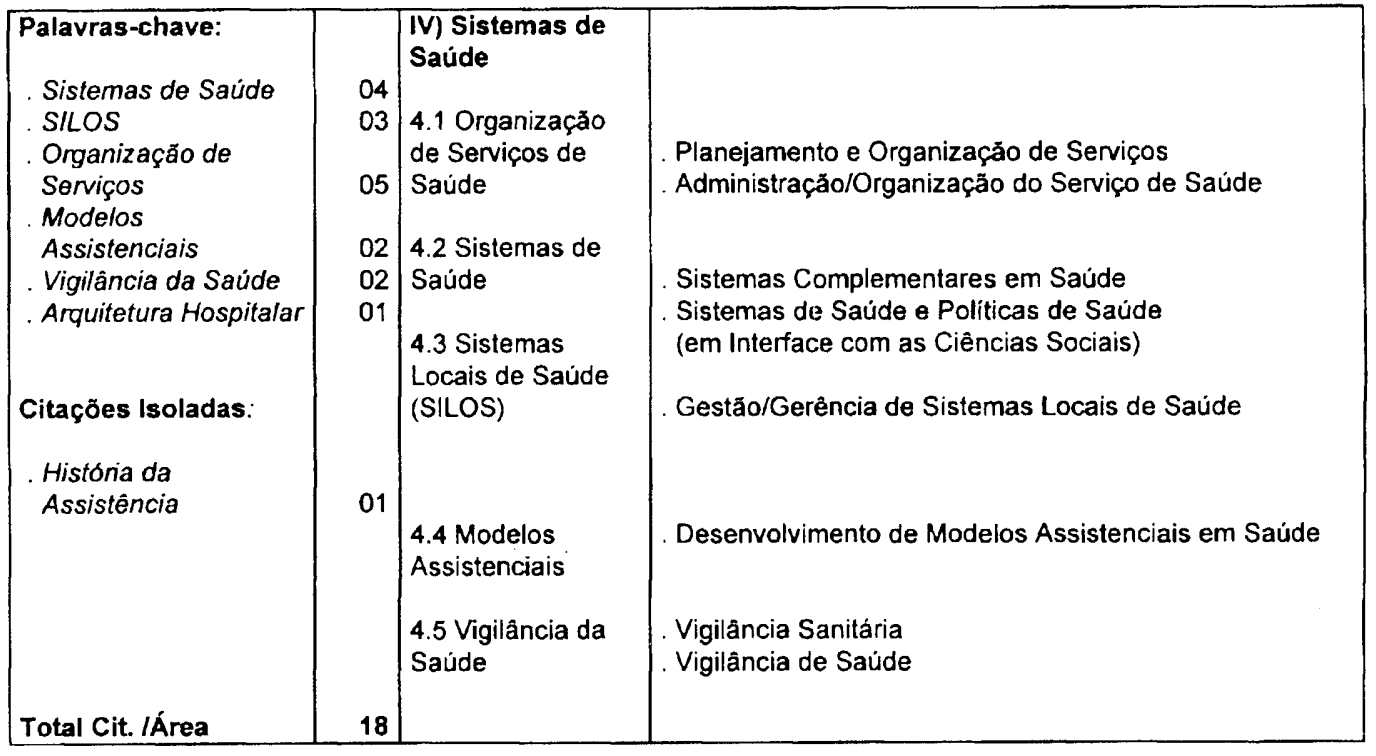

\begin{tabular}{|c|c|c|c|}
\hline $\begin{array}{l}\text { Palavras-chave: } \\
\text { Recursos Humanos } \\
\text { Organização } \\
\text { Tecnológica do } \\
\text { Trabalho em Saúde } \\
\text { Processo de } \\
\text { Trabalho em Saúde }\end{array}$ & $\begin{array}{l}02 \\
02\end{array}$ & $\begin{array}{l}\text { V) Recursos } \\
\text { Humanos em } \\
\text { Saúde } \\
5.1 \text { Gestão de RH } \\
\\
5.2 \text { Formação \& } \\
\text { Capacitaçăo de } \\
\text { RH } \\
5.3 \text { Processo de } \\
\text { Trabalho em } \\
\text { Saúde }\end{array}$ & $\begin{array}{l}\text { Planejamento e Administração de RH } \\
\text { Politica/Administração de RH } \\
\text { Administração de Conflitos } \\
\text { Formaçăo/Capacitação de RH para serviços de saúde } \\
\text { Inserção dos Egressos do Curso ... } \\
\text { Gestão de Processo de trabalho em Saúde } \\
\text { Práticas Profissionais } \\
\text { Organizaçäo Tecnológica do trabalho em Saúde } \\
\text { em Nivel de Atenção Primária } \\
\text { Processo de Trabalho de Médicos e Enfermeiros } \\
\text { no Programa... }\end{array}$ \\
\hline
\end{tabular}

\begin{tabular}{|c|c|c|c|}
\hline $\begin{array}{l}\text { Palavras-chave: } \\
\text { Descentralização } \\
\text {. Controle Social } \\
\text {. Políticas Públicas } \\
\text {. Políticas de Saúde } \\
\text { Citaçōes Isoladas: } \\
\text { Politica e Estratégia } \\
\text { Administrativa } \\
\\
\text { Total Cit.lÁrea }\end{array}$ & $\begin{array}{l}02 \\
03 \\
02 \\
07\end{array}$ & $\begin{array}{l}\text { VI) Políticas de } \\
\text { Saúde } \\
6.1 \text { Politicas de } \\
\text { Saúde } \\
\\
6.2 \text { Politicas } \\
\text { Econômicas e } \\
\text { Sociais } \\
6.3 \text { Controle Social }\end{array}$ & $\begin{array}{l}\text { Avaliação de Politicas e Serviços de Saúde } \\
\text { Politicas e Sistemas de Saúde } \\
\text { Politicas de Saúde e Planejamento } \\
\text { Descentralização/Municipalizaçăo de serviços de saúde } \\
\text { Descentralização e controle social } \\
\text { Política e Estratégia Administrativa } \\
\text { Avaliação de Políticas Públicas } \\
\text { Participaçăo Social e Controle Público }\end{array}$ \\
\hline
\end{tabular}

\begin{tabular}{|l|l|l|l|}
\hline $\begin{array}{l}\text { Palavras-chave: } \\
\text { Economia da Saúde }\end{array}$ & 06 & $\begin{array}{l}\text { VIII) Economia em Saúde } \\
\text { 8.1 Economia (da, em \& e) Saúde } \\
\text { Total Cit./Área }\end{array}$ & 06
\end{tabular}




\section{Anexo 4}

Quadro-resumo da Produção Acadêmica em Planejamento \& Gestão em Saúde no País, por Área Temática e Natureza da Atividade

\begin{tabular}{|l|c|c|c|c|c|c|}
\hline \multicolumn{1}{|c|}{ Áreas Temáticas } & \multicolumn{6}{c|}{ Natureza da Atlvidade } \\
\hline & \multicolumn{2}{|c|}{ Pesquisa } & \multicolumn{2}{c|}{$\begin{array}{c}\text { Ensino de Pós- } \\
\text { Graduaçăo }\end{array}$} & \multicolumn{2}{c|}{ Cooperação } \\
\hline & $\mathbf{N}^{\circ}$ & $\%$ & $\mathbf{N}^{\circ}$ & $\%$ & $\mathbf{N}^{\circ}$ & $\%$ \\
\hline 1. Gestão em Saúde & 25 & 14,6 & 39 & 27,8 & 44 & 43,1 \\
\hline 2. Planejamento em Saúde & 12 & 7,0 & 42 & 30,0 & 20 & 19,6 \\
\hline 3. Avaliaçăo em Saúde & 42 & 24,6 & 8 & 5,7 & 3 & 2,9 \\
\hline 4. Sistemas de Saúde & 21 & 12,3 & 9 & 6,4 & 5 & 4,9 \\
\hline 5. Recursos Humanos & 17 & 9,9 & 13 & 9,3 & 22 & 21,6 \\
\hline 6. Políticas de Saúde & 21 & 12,3 & 17 & 12.2 & 3 & 2,9 \\
\hline 7. Informação em Saúde & 12 & 7,0 & 6 & 4,3 & 3 & 2,9 \\
\hline 8. Economia em Saúde & 06 & 3,5 & 6 & 4,3 & - & - \\
\hline Temáticas Emergentes & & & & & & \\
. Comunicação e Saúde & 04 & 2,3 & - & - & - & - \\
. Espaço e Saúde & 06 & 3,5 & - & - & 02 & 1,96 \\
. Epidemiologia e Serviços & 05 & 2,9 & - & - & - & - \\
\hline TOTAlS * & 171 & 100 & 140 & 100 & 102 & 100 \\
\hline
\end{tabular}

( $\left.{ }^{*}\right)$ Para as atividades de Pesquisa, o número apresentado corresponde ao total de projetos de pesquisa em andamento, distribuídos pelas várias áreas temáticas. Para as atividades de ensino e cooperação, no entanto, optou-se por computá-las mais de uma vez sempre que suas denominações aludiam a mais de uma área temática. Tal procedimento, embora numericamente pouco significativo, fez-se necessário pelo caráter relativamente mais abrangente de certas disciplinas ou cursos, bem como de algumas atividades de cooperação. Neste sentido, os totais apresentados não correspondem exatamente ao número de disciplinas/cursos ou atividades de cooperação técnica, mas ao somatório das citações relativas a essas atividades no conjunto de áreas temáticas. 